\title{
The syndrome of group-focused enmity: the interrelation of prejudices tested with multiple cross-sectional and panel data
}

Zick, Andreas ; Wolf, Carina ; Küpper, Beate ; Davidov, Eldad ; Schmidt, Peter ; Heitmeyer, Wilhelm

\begin{abstract}
Different types of prejudice are usually treated as separate constructs. We propose that they constitute a syndrome of group-focused enmity (GFE), that is, they are related to each other and share a common core that is strongly predicted by a generalized ideology of inequality. Furthermore, GFE components are supposed to have similar predictors and outcomes. An empirical test is presented using structural equation modeling on the syndrome, its causes, consequences, and structural stability over time. The study relies on three German cross-sectional probability samples (each $\mathrm{N}=2,700$ ) and a related panel study (2002, 2003, and 2004). The idea of a GFE syndrome is strongly supported. Future research is discussed, as well as alternative approaches of a common prejudice factor.
\end{abstract}

DOI: https://doi.org/10.1111/j.1540-4560.2008.00566.x

Posted at the Zurich Open Repository and Archive, University of Zurich ZORA URL: https://doi.org/10.5167/uzh-95228

Journal Article

Accepted Version

Originally published at:

Zick, Andreas; Wolf, Carina; Küpper, Beate; Davidov, Eldad; Schmidt, Peter; Heitmeyer, Wilhelm (2008). The syndrome of group-focused enmity: the interrelation of prejudices tested with multiple cross-sectional and panel data. Journal of Social Issues, 64(2):363-383.

DOI: https://doi.org/10.1111/j.1540-4560.2008.00566.x 


\section{THE SYNDROME OF GROUP-FOCUSED ENMITY: The interrelation of prejudices tested with multiple cross-sectional and panel data}

Andreas Zick, Carina Wolf, Beate Küpper, Eldad Davidov, Peter Schmidt and Wilhelm Heitmeyer

This is the accepted version of the following article: Journal of Social Issues Volume 64, Issue 2, pages 363-383, June 2008, which has been published in final form at http://onlinelibrary.wiley.com/doi/10.1111/j.1540-4560.2008.00566.x/abstract or under

DOI: $10.1111 / j .1540-4560.2008 .00566 . x$ 


\title{
THE SYNDROME OF GROUP-FOCUSED ENMITY:
}

\section{The interrelation of prejudices tested with multiple cross-sectional and panel data}

\author{
Andreas Zick, ${ }^{*}$ Carina Wolf, ${ }^{* *}$ Beate Küpper, ${ }^{*}$ Eldad Davidov, ${ }^{* * *}$ \\ Peter Schmidt**** and Wilhelm Heitmeyer*
}

The authors thank the Volkswagen Foundation, Freudenberg Foundation and Möllgaard Foundation for their financial support to the project on Group-focused Enmity.

\footnotetext{
* University of Bielfeld

** University of Marburg

*** GESIS-Central Archive for Empirical Social Research, University of Cologne

**** University of Giessen
}

We thank Tom Pettigrew and Uli Wagner for their helpful comments on an earlier draft of this paper, and Jim Sidanius and Jorge Vala for their inspiring ideas on the topic at the International Workshop on Group-focused Enmity in 2006. The fourth and fifth authors would like to thank Maria Rohlinger for insightful ideas and discussions during the spring seminar 2006 in Cologne, Germany. The fourth author also would like to thank the German Israeli Foundation (GIF) for their financial support. 


\section{$\underline{\text { Abstract }}$}

Prejudices against a variety of stigmatized outgroups are widespread across Europe and other parts of the world. Even though several types of prejudices have been studied extensively they have mainly been treated theoretically and empirically as separate constructs. Contrary to this tradition, we propose that different expressions of prejudice constitute a syndrome of Groupfocused Enmity (GFE). We assume that different types of prejudices are significantly related to each other and share a common core - one that is strongly predicted by a generalized ideology of inequality. Furthermore, we suggest that the components of the GFE-syndrome have similar predictors and basically similar outcomes. We conduct a comprehensive empirical test using structural equation to model the syndrome, its causes, consequences, and its stability over time. The study relies on probability national samples of respondents: three German national samples (each $\mathrm{n}=2700$ ) and a related longitudinal panel study incorporating three measurement points $(2002,2003$, and 2004). The idea of a GFE-syndrome is strongly supported. Necessary future research is discussed, as well as a possible alternative identification of the common prejudice factor.

Keywords: Generalized prejudice, Group-focused Enmity, inequality 
In 1997, the European Union agreed on a struggle to put an end to prejudice and discrimination in article 13 of the Amsterdam Declaration: “...the Council [...] may take appropriate action to combat discrimination based on sex, racial or ethnic origin, religion or belief, disability, age or sexual orientation." A similar aim was generally set by affirmative action policies and initiatives in the United States (e.g., employment discrimination laws). Many different target groups of discrimination, who are named in such declarations, generally share a long history of disparagement. So it has long been held that prejudices against these groups are substantially interrelated. Allport noted: "One of the facts of which we are most certain is that people who reject one out-group will tend to reject other out-groups. If a person is anti-Jewish, he is likely to be anti-Catholic, anti-Negro, anti any out-group" (1954, p. 68). And Adorno, Frenkel-Brunswik, Levinson and Sanford (1950) showed that their proposed syndrome of the authoritarian personality was related to prejudice against several groups (see also Meloen, 1993).

There is considerable empirical evidence that different types of prejudice are significantly interrelated. In addition, studies such as those in the current issue, have repeatedly demonstrated that the various prejudices are predicted by similar factors - such as authoritarianism, social dominance orientation, or relative deprivation. But for the most part, prejudice towards particular outgroups have been analyzed in separate lines of research, and this research rarely employed large probability samples of respondents. We believe that a more comprehensive view of generalized prejudice is needed together with empirical support from large, probability samples.

The current paper attempts to fill this gap. We propose a syndrome of Group-focused Enmity (GFE). In social science, a syndrome is a group of interrelated factors that together form a specific state or condition. The GFE-syndrome encompasses prejudices towards 
different groups that are substantially interrelated with each other, i.e., we adopt Allport's assumption that a person who rejects one out-group is likely to reject other out-groups as well. Additionally, we assume that these prejudices are interrelated in a structural way over a period of time, and that they share something. Different types of prejudice are thought to be interrelated because they all mirror a generalized devaluation of outgroups, i.e. Group-focused Enmity. The central underlying factor is an ideology of inequality that considers different social groups as unequal in value. The criteria are for example economic uselessness, lower levels of civilization, abnormal sexual practices etc. Upholding an ideology of inequality leads to devaluation, discrimination and the legitimization of violence towards several outgroups. The whole pattern of interlinked prejudices sharing a common core and being vastly determined by an ideology of inequality is referred to as the GFE-syndrome.

The GFE-syndrome is held to be partly triggered by the same factors (e.g. authoritarianism and group relative deprivation) with comparable consequences (e.g., discrimination). Major general predictors of prejudices such as authoritarianism and group relative deprivation are thought to have an impact on several types of prejudices that run via the common core. Employing data from three probability surveys and a three-year panel study of the German project on "Group-focused Enmity" (Gruppenbezogene Menschenfeindlichkeit) headed by Heitmeyer (2002), we tested our contentions using structural equation modeling. The structure of the GFE-syndrome is assumed to be stable over a period of time even though the level of approval can vary across time, cultures and individuals.

\section{Prejudices as Components of a Syndrome of Group-focused Enmity}

Although no one has yet conducted a major meta-analytic test of the relationships between various prejudices to the best of our knowledge, evidence from numerous studies measuring the devaluation of various groups supports our contentions. We mention here a 
sampling of this vast literature - most of which employs only samples of convenience. Likewise, Stangor, Sullivan and Ford (1991) noted generalized prejudices represented by affective responses towards Americans, Whites, Asians, Jews, Blacks, Hispanics, Russians, Arabs, and homosexual persons. Kogan (1961) found negative attitudes towards the elderly to be positively related to negative attitudes towards Blacks, ethnic minorities, and both physically and mentally disabled persons. Butler (1969) found ageism to be strongly and positively related to racial and class prejudices. Crandall (1994) even presented evidence that prejudice towards overweight people is linked significantly with both traditional and modern racism. Weigel and Howes (1985) showed that the prejudices of White Americans towards African Americans, homosexual and elderly persons are significantly interrelated. Bierly (1985) as well found substantial relations among theses groups and concluded that prejudice was quite indiscriminate and global. Whitley (1999) demonstrated substantial correlations between prejudices towards African Americans and homosexual persons whether measured as affective prejudices, stereotyping, or attitudes towards equality enhancement. Throughout this literature, negative attitudes towards homosexual persons and women seem to be closely linked (e.g., Weinberger \& Millham, 1979).

Beside these intercorrelations among different types of prejudice, a few studies have presented evidence for generalized prejudice. Using confirmatory factor analyses, Heyder and Schmidt (2003) uncovered a second-order factor (i.e., a higher level factor that accounts for the lower order factors) constituted by anti-Semitism, anti-immigrant sentiments and ingroup favoritism in a German national survey. Guimond and his colleagues (2003) developed a highly reliable scale $($ alpha $=.94)$ of prejudices towards 17 ethnic outgroups in France. Bratt (2005) investigated the structure of outgroup attitudes towards five non-Western immigrant groups (Turks, Somalis, Pakistanis, Kosovo Albanians, Vietnamese) among adolescents from the majority group in Norway. He found that the prejudices are substantially related to a second-order factor (but see Bratt's analyses of other factorial solutions). Using exploratory 
factor analysis, Ekehammar and his co-workers (2004) reduced modern racism, modern sexism, prejudice towards mentally disabled, and towards homosexual persons into a single factor of generalized prejudice in Sweden. Comparably Backström and Björklund (2007) showed that classical and modern racism and sexism and classical and modern prejudices toward people with impaired development are represented by a general prejudice factor. Ekehammar et al. (2004) argue that their results support Allport's (1954) idea of prejudice as a personality trait. However, our study extends their approach in three respects: We take more outgroups into account, as well as multiple points of time instead of cross-section and an external validation criterion, i.e. an ideology of inequality.

The results described support our contention that various prejudices can be understood as components of a GFE-syndrome. Our basic assumption is that all features that differentiate outgroups from the normative consensus of a dominant group can serve to indicate deviance, while also confirming the normalcy of the ingroup (e.g., by pointing to an outgroup's gender, sexual orientation, religious belief, or appearance). Normalcy can be established either by a majority or by norms and standards defined by dominant groups. Therefore, all prejudices towards any target group marked as different in a negative sense can become components. Prejudices can also be expressed by any group (dominant or subordinate, majority or minority), even though gaining dominance is more likely for members of a majority than a minority and prejudices usually serve the dominant group's own purpose better (see Jost \& Burgess, 2000).

Nevertheless, outgroups are not entirely arbitrary. Cultures offer a pallet of wellknown outgroups. Some groups are marked as outgroups cross-culturally - such as those defined by gender, age, or physical deviance. Others are more cultural- or time-specific such as the Maghrébins in France. For our analyses, we posit nine constitutive components for a current German GFE-syndrome reflecting the target groups called in the new German anti- 
discrimination law: ${ }^{1}$ (1) Racism is a strong expression of racially legitimized inequality between groups. It asserts the idea of superiority of one group on the basis of biological or natural differences. Against the background of National Socialist ideology, racism assumes

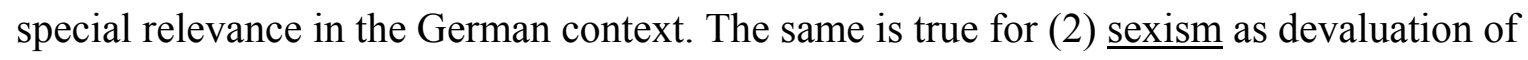
women. (3.) Xenophobia is here defined as the devaluation and rejection of immigrants. Repeated research indicates that negative attitudes towards immigrants are widespread across Germany (e.g. Wagner, van Dick \& Zick, 2001). (4) Anti-Semitism is a deeply embedded prejudice towards Jews and Judaism, which is still shared among Germans in its classical form, but even more in its newer transformations (e.g. Zick \& Küpper, 2005). (5) Since September 11, 2001, Islamophobia is on the agenda across the western world; it includes hostility towards Muslims and negative attitudes towards Islam. Both anti-Semitism and Islamophobia are prejudices towards different religious groups in Germany's predominantly Christian culture. (6) Devaluation of homosexual persons (gays and lesbians), (7) disabled and (8) homeless persons all embrace negativity towards groups who are outside mainstream society. Even not called out in the anti-discrimination law, homeless persons are considered as particular visible group systematically excluded from society in the public space, from welfare, in the housing- and job-market. Homeless persons have become victims of rightwing motivated hate crimes apparently sometimes substituting other possible victims such as foreign looking, homosexual and disabled persons. (9) The last component is defined as generalized prejudice against newcomers (e.g., new neighbors, colleagues, classmates), following Elias and Scotson (1965) labeled here as precedence rights of the established. Some target groups are more clearly defined, such as Jews and homosexual persons, while others are defined rather vaguely, such as immigrants and newcomers to an area. However, all GFEcomponents incorporate group-based devaluation and reflect inequality between groups, focusing mainly on either the dominant or the subordinate group. 


\section{A Common Core: The General Ideology of Inequality}

We argue that several types of prejudice serve to maintain or enhance group status and to keep lower status groups in their inferior place (e.g. Blumer, 1958; Bobo, 1999). Therefore, a critical function of prejudices is to legitimize group-based inequality. We assume that several types of prejudices are not only related to each other but that they share a common core - namely a generalized devaluation of outgroups. We assume that this common core is strongly determined by an ideology of inequality. According to Social Dominance Theory prejudices like other legitimizing myths rest on an individual's social dominance orientation (SDO), which can be defined as “... a very broad orientation expressing one’s general endorsement of group-based inequality" (Sidanius, Pratto \& Levin, 1996, p. 387). Since SDO is defined as generalized group-based inequality it should reflect such an ideology of inequality.

If individuals accept group-based inequality in general, they tend to devalue multiple outgroups. However, which outgroups are focused on as target group depends on the options a specific society offers. Therefore, while means can vary between individuals according to their unique acceptance of the ideology of inequality, the syndrome's structure (i.e., the linkage of specific prejudices) is assumed to be ubiquitous within one society at a given time. The same is expected for the content of the single GFE-components. ${ }^{2}$ However, the content of the structure might vary between societies or cultures, and there may also be long term variation within cultures over time (see papers in this issue). Thus, while prejudice towards homosexual persons are supposed to be part of the GFE-syndrome in Germany nowadays, it might not be part of a GFE-syndrome in a more liberal country or it might fall out of the GFE-syndrome in Germany in the future with increasing acceptance of homosexuality in society. The components of the GFE-syndrome depend on societal offered justifications for the agreement to prejudices and on demands to suppress them, and also on the degree of 
attention an individual pays to such options (see Crandall \& Eshleman, 2003 for an overview).

\section{$\underline{\text { Common Causes and Outcomes }}$}

If there is such a GFE-syndrome, it is reasonable to assume that the same personal and situational factors will predict different types of prejudices. Moreover, their impact should be directed via the common core. Agnew, Thompson and Gaines (2000) tested distal and proximal factors that explain a generalized negative attitude towards several outgroups. The current paper takes a first step in focusing on an analysis of two predictors well-known to be empirically particular powerful and that were available in the data set - authoritarianism as a personal factor and Group Relative Deprivation as a perceived situational factor.

Since Adorno et al.'s (1950) Authoritarian Personality and the introduction of Altemeyer's $(1981,1988)$ Right-Wing Authoritarianism Scale (RWA), numerous studies reveal that an authoritarian orientation is strongly related to a great variety of prejudices. Substantial correlations have also been found between RWA and SDO (e.g. Duckitt, 2001; Sidanius \& Pratto, 1999; Whitley, 1999). RWA and SDO both predict generalized prejudice (e.g. Ekehammar et al., 2004). However, Ekehammar et al. (2004) found that SDO has a stronger direct impact on generalized prejudice than RWA and that the impact of RWA is also indirectly transmitted by SDO.

Prejudice is also a consequence of situational influences such as an individual's perceived social position (Smith, 1981). Many studies show that Group Relative Deprivation (GRD) defined as the perceived disadvantage of one's own group in comparison to other relevant groups (Runciman, 1966) is an important predictor of prejudice (see Pettigrew et al., in press). Those who feel group deprived are prone to prejudice. 
Pursuing the idea of a GFE-syndrome, we expect the impact of authoritarianism on specific prejudices to be mediated by a generalized ideology of inequality as a second-order factor of several types of prejudices - that is, authoritarianism influences single prejudices via their common core. As a more severe test of the GFE-syndrome, we test the same assumption for GRD focused on immigrants designed to explain xenophobia as a specific type of prejudice.

Whereas authoritarianism and GRD refer to common causes of the syndrome, we also predict that different components of the GFE-syndrome have similar consequences such as the intention to discriminate against outgroups (see Wagner, Christ \& Pettigrew in press). Traditionally analyses show relations between prejudice and corresponding discrimination with respect to the same group (see Dovidio, Brigham, Johnson \& Gaertner, 1996; Schuetz \& Six, 1996). We go beyond these findings and assume that the common core predicts discriminatory intentions even regarding specific groups and controlling for the attitudes towards the respective group.

\section{Empirical Tests of the Syndrome of Group-focused Enmity}

To sum up in empirical terms, we hold that different types of prejudices constitute a syndrome of GFE. Thus, we expect the nine GFE-components to be moderately to highly intercorrelated. We also hold that the GFE-components can be attributed to a single secondorder factor labeled GFE. We presume that this factor is strongly predicted by the individual's acceptance of a generalized ideology of inequality. However, we do not anticipate that different types of prejudices are interrelated to an identical strength and contribute as much to the common factor across time. The whole GFE-syndrome should be predicted by authoritarianism and GRD, and in turn it should predict discriminatory intentions towards 
specific groups (but see footnote 12). Causes as well as outcomes show their influence via the second order factor GFE.

\section{$\underline{\text { Samples and Measures }}$}

Data. The analyses are based on five data sets conducted during 2002 (study 1, $\mathrm{N}=$ 2,722), 2003 (study 2, $\mathrm{N}=2,722$ ) and 2004 (study 3, $\mathrm{N}=2,656$ ) by a professional survey institute via standardized telephone interviews. The three samples are representative of the German adult population (16 and older) without migration background with respect to the nationality of the respondents' parents or grandparents. From the 2002 sample, 1,383 respondents were re-interviewed in 2003 (panel-wave 2) and 825 from this same pool were re-interviewed in 2004 (panel-wave 3). Missing values were replaced in all analyses with multiple imputations using expectation maximization (EM) estimates (Schafer \& Graham, $2002)^{3}$

Measures. The nine components of the GFE-syndrome were measured by items used successfully in other surveys and pre-tested for our study. Respondents indicated their agreement on a four-point response scale $(1=$ fully disagree, 2 = rather disagree, $3=$ rather agree, 4 = fully agree). See table 1 for final items, means, standard deviations and intercorrelations.

--- insert table 1 about here ---

In our basic data set, main-study 1, xenophobia was measured by eight items; anti-

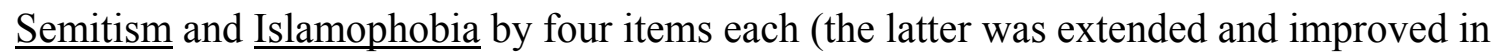
2003), precedent rights of the established and racism by three items each, and the devaluation

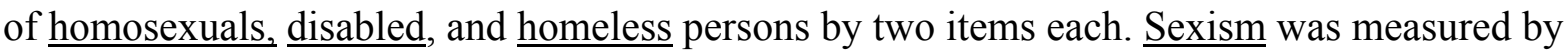


only one item in 2002 but in the following also with two items. Three SDO-items taken from Sidanius and Pratto (1999) (e.g., "Some groups of people are just more worthy than others.") measured the ideology of inequality. Authoritarianism employed four indicators based on Altemeyer (1981) (e.g., “Crime should be punished more harshly.”). Group Relative Deprivation was seized by the single question "If you compare the economic situation of Germans with that of the immigrants living in Germany, how do the Germans fare by comparison?" Intended discrimination of immigrants and Muslims was measured by two items that were available in the data set (Immigrants: "I never would buy a car from an immigrant4."; Muslims: "I would have problems to move into an area in which many Muslims are living.").

\section{$\underline{\text { Hypotheses, data analyses procedure and results }}$}

We performed three basic analytical steps encompassing a series of sub-analyses: 1a) Analyses of the internal structure of interrelations between the GFE-components and the second-order factor GFE and 1b) a cross-validation. 1c) Estimating the stability of the syndrome over time; 2) Testing the nature of the second-order factor by estimating its relation to SDO. 3) Analyzing the causes and consequences of GFE. For greater clarity, we have presented each set of specific hypotheses and their corresponding analyses step by step (see also table 2). Our analyses used the statistical program AMOS 5 (for all the results reported in this paper and further analyses not reported, see http://www.unigiessen.de/fb03/politik/personen/schmidt/jsi.html).

--- insert table 2 about here ---

\section{1a) Internal structure.}


According to our hypotheses, responses to the prejudice items towards nine different outgroups can be explained by nine first-order factors (racism, xenophobia, etc.) in each data set and at each point of time $(\underline{\mathrm{H} 1})$. In turn, the nine first-order factors are explained by one

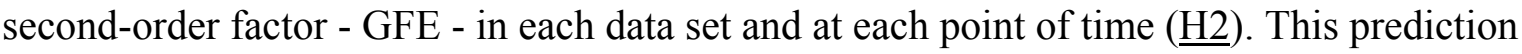
requires the covariation among the nine first-order factors to be explained fully by the secondorder factor of GFE. Cognitive ability is strongly related to the level of education (Zaller, 1995). To make sure that respondents did not evaluate different outgroups distinctively just because of less complex cognitive abilities, we tested $\mathrm{H} 1$ and $\mathrm{H} 2$ to hold for all levels of education $(\underline{\mathrm{H} 3})$. Furthermore, we did not expect the meaning of the GFE-components to vary depending on the level of education (metric invariance). Therefore, we postulate that the relationship between the GFE-components and their indicators is the same across educational groups. Finally, it remains is an open question, as to whether the meaning or composition respectively of the second-order GFE-factor is the same across the different educational levels - that is, whether the loadings of the first-order prejudice factors on GFE are equal across these groups. However, we will also test for the invariance of the second-order factor GFE.

We tested $\mathrm{H} 1$ and $\mathrm{H} 2$ conducting second-order confirmatory factor analyses (CFA) on the bases of study 1 and cross-section study 2 and cross-validated the results in the other data sets (cross-section study 3 and panel wave 2 and 3). In the first step, nine separate first-order CFAs were conducted for each prejudice component. The best two items per construct were selected on the basis of their factor loadings for a parsimonious model of GFE. ${ }^{5}$. An exception was sexism in study 1 (2002) because traditional sexism here was only measured by one item. Thus, 17 items in study 1 and 18 items in cross-section study 2 respectively were basis of the subsequent $2^{\text {nd }}$ order CFA with GFE as a second-order factor ${ }^{6}$ hypothesized to explain the latent (except for sexism in 2002 with only one observed indicator) first order prejudice constructs. 
As predicted, the $2^{\text {nd }}$ order CFA based on study 1 and cross-section study 2 clearly revealed separable first-order prejudice constructs explaining responses to the items $(\mathrm{H} 1)$ and one second-order factor (labeled as GFE) explaining their intercorrelations (H2). According to Hu and Bentler (1999) and Marsh, Hau and Wen (2004), the fit of the model is acceptable (for model fits see figure 1 and table 2).

Nevertheless, two problems occurred. First, prejudice towards disabled people does not belong to GFE; the factor loading of the first-order construct on the second-order factor was rather low. Upon re-examination, we noted that prejudice towards disabled persons triggered negative intergroup emotions ("feel unsure"; "feel unpleasant / uneasy") more than the other measures. Thus, its deviant structure may reflect this different content in the measurement of prejudice against disabled persons. Therefore, we removed this component from further analyses.

A second problem involves the close relationships between some of the components as indicated in their residual correlations - sexism and devaluation of homosexual persons, sexism and racism, and xenophobia and Islamophobia. For all of these inter-component correlations, the overlapping of content offers a possible explanation. Both sexism and the devaluation of homosexual persons stress conservative attitudes towards gender roles and refer to gender stereotypes (e.g., Weinberger \& Millham, 1979). Women and male homosexuals share similar stereotypes of femininity. However, the strong relationship between the two components may simply reflect that sexism is represented by only one item. A recalculation of the model using the panel-studies wave 2 and. 3 and the cross-sectionstudies 2 and 3 including two items for sexism showed improved model fits by adding sexism into the CFA. Nevertheless, sexism still correlates directly with the devaluation of homosexual persons.

The strong relation of sexism and racism may be grounded in the similarity of the group markers used to legitimize inequality. Both components refer to biological differences 
and follow the cruel argument that women and non-whites both are subordinate groups by nature. Xenophobia and Islamophobia might be strongly related, because respondents may have had the same group of people in mind when answering. ${ }^{7}$ Thus, we decided to allow direct correlations between the residuals in all three cases.

--- insert figure 1 about here ---

Hence, the cross-validation analyses and the following validation analyses have as their starting point a model with one second-order factor of GFE connecting eight syndrome components, of which three pairs are correlated via their residuals.

\section{1b) Cross-validation}

We cross-validated both models in the three remaining data sets.-Acceptable fit measures were found with these data sets for the corresponding model. Even though other variants of the model had acceptable fits, the selected model with one second-order factor of GFE and no direct interrelations between the first-order constructs but three residual correlations fits best in all five data sets.

Based on cross-section study 2, we next checked to determine if a second-order factor GFE can be found at different levels of education (H3). Furthermore, we tested whether the meaning of the different prejudice constructs and the $2^{\text {nd }}$ order factor GFE are equal across different levels of education. Thus, we performed multi-group comparisons comparing the GFE-second-order model for three levels of education. As expected, the model fits the data well in all three educational levels $\left(\chi^{2}=747.761, \underline{\mathrm{df}}=279, \mathrm{p}<.001, \chi^{2} / \mathrm{df}=2.68, \underline{\mathrm{CFI}}=.958\right.$, $\underline{\text { RMSEA }}=.025, \underline{\mathrm{p} \text {-close }}=1.00)$.

The test for invariance of the prejudice factors and their second-order Group-focused Enmity, however, yielded mixed results. According to the chi-square difference test, the 
stricter models offer about a 5\% worse fit than the model that assumes no invariance across the different groups. ${ }^{8}$ However, since all global fit measures showed increasingly better fits for the stricter models, we decided to accept the strictest model assuming invariance in the meaning of prejudice factors and the second order factor GFE across all levels of education (no invariance: $\chi^{2}=747.761, \underline{\mathrm{df}}=279, \underline{\mathrm{p}}<.001, \underline{\chi^{2} / \mathrm{df}}=2.68, \underline{\mathrm{CFI}}=.958, \underline{\mathrm{RMSEA}}=.025, \underline{\mathrm{p}}-$ $\underline{\text { close }}=1.00$; invariance of prejudice factors: $\chi^{2}=777.272, \underline{\mathrm{df}}=295, \mathrm{p}<.001, \underline{\chi^{2} / \mathrm{df}}=2.635$, $\underline{\mathrm{CFI}}=.957, \underline{\mathrm{RMSEA}}=.025, \underline{\mathrm{p} \text {-close }}=1.00$; invariance of second-order factor GFE: $\chi^{2}=$ $\left.1.926, \underline{\mathrm{df}}=309, \mathrm{p}<.001, \chi^{2} / \mathrm{df}=2.595, \underline{\mathrm{CFI}}=.956, \underline{\mathrm{RMSEA}}=.024, \underline{\mathrm{p}-\mathrm{close}}=1.00\right)$.

While the global test supported at least no major differences between the various education groups, specific tests revealed which of the paths showed (minor) differences: For instance, the regression coefficients of anti-Semitism (.76 vs. .55) and the devaluation of homosexual persons (.64 vs. .45) on the second-order factor were higher for highly educated than for poorly educated respondents. Moreover, the error variance of GFE was lower in the higher education group indicating that this group renders fewer chance responses (e.g. Zaller, 1995).

These results provide strong empirical evidence for a GFE-syndrome. It holds for both high and low levels of education with equal meaning for the prejudice components. There are somewhat different patterns of GFE across educational groups, though these differences are small.

\section{1c) Stability over time}

Two features of general stability are especially relevant for this paper: (1) the stability of construct meanings and (2) positional stability, i.e. stability in the interindividual ranking of prejudiced attitudes over time. Mean differences are addressed elsewhere (Davidov, Schmidt, Wolf, \& Heitmeyer; in prep). Different types of prejudice are expected to be stable in their meaning over time; that is, the loadings of the items on their first-order prejudice 
factors should be invariant ( $\underline{\mathrm{H}} 4)$. However, we do not expect the loadings of the prejudice factors on GFE to be invariant ( $\underline{\mathrm{H} 5})$, that is we do not think the meaning of GFE is constant over time (see theoretical section).

To examine positional stability, we predict that the GFE-syndrome at $\mathrm{t} 1$ will predict the syndrome at $\mathrm{t} 2$, which in turn will predict the syndrome at $\mathrm{t} 3$, while the GFE-syndrome at $\mathrm{t} 1$ is not expected to predict the syndrome directly at $\mathrm{t} 3$ (6ㅜ) after checking for $\mathrm{t} 2$. This is because the effect from GFE in 2002 (t1) to GFE in 2004 (t3) is expected to be fully mediated by GFE in 2003 (t2) (Jöreskog \& Sörbom, 1977). Furthermore, we predict stability in the ranking of prejudiced attitudes over time, without knowing from prior work the exact stability coefficient we can expect $(\underline{\mathrm{H} 6 \mathrm{~b}})$. H4 to H6 are tested by specifying autoregressive models (Meredith, 1993) with three reference dates - 2002, 2003, and 2004. We also tested another panel model with only the 2003 and 2004 data to take the new measures of sexism and Islamophobia into account.

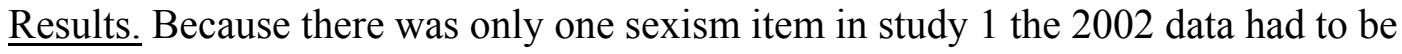
excluded from this test due to identification problems. The fit measures of the autoregressive panel model over three time points (without sexism) are satisfactory $\left(\chi^{2}=4653.414 \underline{\mathrm{df}}=735\right.$, $\left.\mathrm{p}<.001, \underline{\chi^{2} / \mathrm{df}}=6.331, \underline{\mathrm{CFI}}=.926, \underline{\mathrm{RMSEA}}=.045, \underline{\mathrm{p} \text {-close }}=1.00\right)$. As hypothesized each GFE measure is significantly predicted by the preceding GFE measure without any direct path from GFE in $\mathrm{t} 1$ to GFE in $\mathrm{t} 3$ (H6a). The second-order GFE factor is highly stable over time (H6b). This means that those individuals who are comparatively highly prejudiced at time point 1 are again comparatively highly prejudiced at time point 2 and 3 . The standardized regression coefficient of GFE in $\mathrm{t} 1$ on GFE in $\mathrm{t} 2$ is $\underline{\text { beta }}=.93$ and the regression coefficient of GFE in $\mathrm{t} 2$ on GFE in $\mathrm{t} 3$ is beta $=.96$.

All first-order prejudice measures have high autocorrelations. That is, xenophobia in $\mathrm{t} 1$ is correlated with xenophobia in $\mathrm{t} 2$ and $\mathrm{t} 2$ is correlated with $\mathrm{t} 3$. These autocorrelations are 
all statistically significant (with the one exception of the autocorrelation between the measurement errors of the second Islamophobia item in time points 1 and 3).

The model also supported invariance across time for the prejudice measures $\left(\chi^{2}=4707.911, \underline{\mathrm{df}}=749, \underline{\mathrm{p}}<.001, \chi^{2} / \mathrm{df}=6.286, \underline{\mathrm{CFI}}=.925, \underline{\mathrm{RMSEA}}=.045, \underline{\mathrm{p} \text {-close }}=1.00\right)$. But there was no such support for invariance of factor loadings between the GFE-components and the second-order factor GFE across time $\left(\chi^{2}=4909.633, \underline{\mathrm{df}}=761, \underline{\mathrm{p}}<.001, \chi^{2} / \mathrm{df}=6.452\right.$, $\underline{\mathrm{CFI}}=.922, \underline{\mathrm{RMSEA}}=.045, \underline{\mathrm{p}-\mathrm{close}}=1.00)($ see footnote 7$)$. Hence, as predicted, the meaning of prejudice constructs is equal across all three time points whereas the composition or meaning of GFE varies across the three time points (H4, H5).

Additionally, we tested the panel model for the time points 2003 and 2004 with the improved measures of sexism and Islamophobia $\left(\chi^{2}=2,546.894, \underline{\mathrm{df}}=423, \underline{\mathrm{p}}<.001, \chi^{2} / \mathrm{df}=\right.$ $6.021, \underline{\mathrm{CFI}}=.945, \underline{\mathrm{RMSEA}}=.044, \underline{\mathrm{p} \text {-close }}=1.00) .{ }^{9}$ Once again, the syndrome's stability between 2003 and 2004 is very high ( $\underline{\text { beta }}=.95)$

To sum up, the meaning of the prejudice constructs again remained constant. With only two time points and sexism included, we even found the composition of GFE to remain the same over time ${ }^{10}$.

\section{2) Common core of an ideology of inequality}

Since the ideology of inequality is assumed to be a strong predictor of GFE, we expect a positive effect of the ideology of inequality, as measured by SDO, on the second-order GFE factor. This necessarily implies that GFE and the ideology of inequality (SDO) are two distinct concepts. We can test this by finding out whether the correlation between GFE and SDO is lower than 1 . However, if the two were conceptually the same thing, then the correlation between the second-order factor GFE and SDO would be equal to 1. In our test the correlation between GFE and SDO is extremely high $(\underline{r}=.85)$ but different from 1 (the fit of the model is reasonable: $\chi^{2}=784.099, \underline{\mathrm{df}}=140, \underline{\mathrm{p}}<.001, \chi^{2} / \mathrm{df}=5.601, \underline{\mathrm{CFI}}=.955, \underline{\mathrm{RMSEA}}$ 
$=.041, \underline{\mathrm{p} \text {-close }}=1.00)$. Hence, as expected SDO and GFE are two closely linked but in the strict sense distinct concepts. The standardized effect (regression coefficient) of SDO on GFE was beta $=.85$.

\section{3) Common causes and consequences}

We checked the relationships between the GFE-syndrome and its determinants and consequences to establish construct validation. Since this is only a validation test we do not account for the detection of relationships between the different predictors Group Relative Deprivation, Authoritarianism and Social Dominance Orientation. Three hypotheses are relevant: First, we predict that GFE mediates the relationship between authoritarianism and the eight single prejudice components of the syndrome ( $\underline{\mathrm{H} 8})$. Second, we hypothesize that GRD focused on prejudice towards immigrants will have a significant effect not only on one specific type of prejudices but on all other prejudice measures, and that this influence goes via GFE (보). Third, we predict that GFE is positively related to discriminatory intentions. Not only will specific component of GFE (e.g., xenophobia) explain specific forms of discrimination (e. g. intended discrimination against immigrants; see Wagner et al. in this issue), but other prejudices will also help explain such intentions via the second-order factor GFE ( $\underline{\mathrm{H} 10})$. We expect GFE to mediate fully these effects of the prejudice factors on discriminatory intentions; thus, there should be no need in the model for any direct effects from the prejudice measures to discriminatory intentions.

We tested H8 and H9 by conducting SEMs with the GFE-factor as dependent variable and authoritarianism with three items as latent factor and GRD with one observed indicator respectively as predictors. The models were specified only with direct paths from the predictors to GFE, but not its components. Next we checked on whether additional paths were necessary due to the amount of the modification indices. The procedure in testing H10 was analogous with GFE as predictor variable and the latent construct discrimination against 
Muslims and immigrants (one item each) as dependent variables. To exclude spurious relationships, we checked for the effects of the demographic variables education, age, gender, and income in all three models.

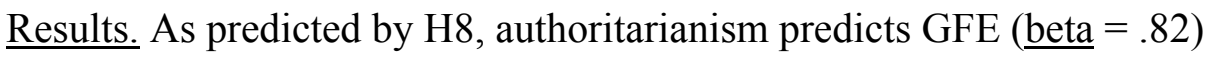

$\left(\chi^{2}=1477.381, \underline{\mathrm{df}}=227, \underline{\mathrm{p}}<.001, \underline{\chi^{2}} / \underline{\mathrm{df}}=6.508, \underline{\mathrm{CFI}}=924, \underline{\mathrm{RMSEA}}=.048, \underline{\mathrm{p}-\mathrm{close}}=955\right)$. However, model indices suggested an additional direct path from to authoritarianism to sexism. Even though doing this did not substantially change model fit, we have to state that GFE does not fully mediate the strong link between authoritarianism and sexism.

As H9 held, GRD predicts all the prejudice components via GFE $(b=.32)$ with a reasonably good fit of the model $\left(\chi^{2}=831.174, \underline{\mathrm{df}}=165, \underline{\mathrm{p}}<.001 ; \underline{\chi^{2}} \underline{\mathrm{df}}=5.037, \underline{\mathrm{CFI}}=.949\right.$, $\underline{\operatorname{RMSEA}}=.041, \underline{\mathrm{p} \text {-close }}=1.00)$. Even though GRD was focused on the comparison between Germans and immigrants, no direct paths between GRD and xenophobia or Islamophobia were necessary. This means that GFE almost completely mediated the links between GRD and xenophobia and Islamophobia (see figure 2). If the direct paths from GRD on xenophobia $(\underline{\mathrm{b}}=.15)$ and Islamophobia $(\underline{\mathrm{b}}=.13)$ are allowed, the effect of GRD on GFE is only slightly reduced $(\mathrm{b}=.26)\left(\chi^{2}=779.171, \underline{\mathrm{df}}=163, \underline{\mathrm{p}}<.001, \underline{\chi^{2}} / \underline{\mathrm{df}}=4.334, \underline{\mathrm{CFI}}=.952, \underline{\mathrm{RMSEA}}=.039\right.$, $\underline{\mathrm{p} \text {-close }}=1.00)$.

As expected by H10, GFE determines directly and positively $(b=.79)$ discriminatory intentions towards immigrants and Muslims $\left(\chi^{2}=939.591, \underline{\mathrm{df}}=188, \underline{\mathrm{p}}<.001, \chi^{2} / \underline{\mathrm{df}}=4.998\right.$, $\underline{\mathrm{CFI}}=.946, \underline{\mathrm{RMSEA}}=.041, \underline{\mathrm{p} \text {-close }}=1.00)$. However, if we introduce the direct paths from prejudice against the discriminated target groups, the effect of GFE on discrimination is strongly reduced $(b=.19)$, but still significant and meaningful $\left(\chi^{2}=889.430, \underline{\mathrm{df}}=186, \underline{\mathrm{p}}<\right.$ $\left..001, \chi^{2} / \underline{\mathrm{df}}=4.782, \underline{\mathrm{CFI}}=.950, \underline{\mathrm{RMSEA}}=.039, \underline{\mathrm{p} \text {-close }}=1.00\right)$.

To sum up, authoritarianism as a general predictor of prejudice affects only GFE directly and does not affect the specific prejudice factors directly - except for sexism. As a target group-specific predictor of prejudice, GRD regarding immigrants affects not only 
xenophobic and islamophobic attitudes, but also all of the other components of the syndrome via GFE. Moreover, the intended discrimination towards a specific target group is not only predicted by its respective prejudice component but also by GFE.

\section{$\underline{\text { Conclusions and Questions }}$}

Even though each target group of prejudice and discrimination is unique and stereotypes of groups differ, they all share the fate of being victims of prejudice and discrimination. We successfully tested a syndrome of GFE that includes prejudice towards several outgroups related to one another, sharing a common factor of a generalized ideology of inequality, and possessing common predictors and consequences. Three German probability surveys and a three-wave panel study give empirical support to these contentions and reveal a remarkable stability over time of these patterns with few exceptions.

Remarkably, even though large numbers of our respondents - e.g. females and newcomers in particular - are member of outgroups as well, sexism is highly correlated with prejudice against other groups (see as well Ekehammar et al., 2004), and especially with prejudice against homosexual persons (Weinberger \& Millham, 1979). Models did not differ between men and women (see homepage). Similarly, the proposition of established rights is closely linked to the other components of GFE. Although both components - sexism and established rights - do not focus on minorities in a narrow sense they are as well linked to a general GFE-factor.

However, we uncovered one exception: negative attitudes towards disabled people were not interlinked closely to the other prejudices and the common core of generalized devaluation of outgroups as hypothesized. This exception may be attributable to measurement factors. While other prejudice measures characterized cognitive beliefs, the items used to measure prejudice against disabled persons in this study tapped affect. Further research using other measures to test this component is needed. Additional research is also needed to 
investigate if covert expressions of derogation such as subtle prejudice (Pettigrew \& Meertens, 1995) are also linked to the GFE-syndrome.

Bratt (2005) recently suggested that varied prejudices relate to group status differences. We show that different types of prejudice share a common core of a generalized devaluation of outgroups labeled as GFE that is strongly determined by an ideology of inequality. Our empirical results suggest that the common factor of multiple prejudices is highly related to SDO that presents such an ideology of inequality by definition, but not identical with SDO. Again, this could be explained by measurement differences, since SDO is recorded only by three items which cover only the sub-dimension group-based dominance and not the second sub-dimension opposition to equality (Jost \& Thomson, 2000). Additionally SDO may not reflect a generalized ideology of inequality; that is, the definition of SDO has to be reconsidered. Or conversely, the common core of several prejudices is not only predicted by an ideology of inequality, but also by such possible other factors such as hate (c.f. Brewer, 1999). Even more serious from a theoretical point of view is the possibility that there is more than just one common core of prejudices. There might be sub-patterns of prejudices within the syndrome with some types of prejudices which are more highly related with each other than with other prejudices that share a slightly different core. Future research needs to examine possible sub-patterns that would imply a third order latent factor.

The strong correlations of GFE and SDO shows that indeed ideologies do play a role. As well, other, non-ideological reasons such as overall bad mood or conscious suppression to report prejudices e.g. due to social desirability forces might cause the syndrome-like pattern. We do not argue that following an ideology of inequality is deeply embedded within an individual and not prone to other, contrary norms or moods. However, implicit and nonreactive measures of prejudice have shown strong relations to scale measurement (e.g., Greenwald, McGhee, \& Schwartz, 1998). 
We have shown that several types of prejudice can be traced back to a common source representing something similar to an ideology of inequality. If individuals accept group-based inequality, this guides the way they look at the world, their related specific attitudes towards lower status groups and their behavior. Finally, this serves to stabilize or improve status relations. This is true for dominant groups (Sidanius \& Pratto, 1999), but it can also be true for subordinate groups. This can be the case if subordinate groups compare themselves to even lower-status groups. Alternatively, as Jost and Burgess (2000) argue, subordinate groups want to stabilize the hierarchical system either because it is norm congruent or because they profit from the system similarly to low-status group members.

Given our consistent findings of a GFE-syndrome, existing theories on prejudice must be reconsidered. Young-Bruehl (Pettigrew, 1998), for example, has argued that there is no generalized prejudice, only unique individual prejudices. Research needs to focus on the similarities among different types of prejudices and highlight their linkage. Special peculiarities of particular prejudices also need to be worked out. Other possible general predictors - anomia and such group-specific predictors as intergroup contact - need to be taken into account as common causes of the GFE-syndrome. As an implication for intervention programs against prejudice and discrimination our findings suggest to address a variety of prejudices simultaneously and point to their linkage.

All eight GFE components focus on groups marked as societal outgroups that are perceived as different from the dominant group either because of their religious orientation (Jews and Muslims), sexual orientation (homosexual persons), ethnic-cultural background (immigrants), appearance (Blacks), gender (women), their form of living (homeless persons), or just because they are newcomers. These eight components make sense for the present German context, but may not be considered conclusive, universal or invariant across cultures and times. With changing conditions and political topics, new groups might become parts of the syndrome - such as victims of AIDS (Devine, Plant \& Harrison, 1999), the elderly (see 
JSI, Vol. 61, No. 2), the unemployed, or welfare recipients. At the same time groups belonging to the syndrome may disappear from it.

The critical question to be asked is which group under what conditions becomes part of the GFE-syndrome? From a sociological perspective - like that of Social Disintegration Theory (Anhut \& Heitmeyer, 2000), this depends on the level of status threat. From an individual perspective, it can depend on the motive to allay feelings of insecurity. From a political perspective of power, it can depend on the changes in the relations between groups. Such processes are combined by the attempt to manifest social order as a basis of standards of normalcy and security. The connecting link of the three paths of explanation is the motive to maintain and establish superiority. Therefore, it is necessary to demonstrate power; and an effective way to do this is to demonstrate the supposed inferiority of weak groups that is often initiated and mobilized by elite groups. The key role to avoid such processes seems to be the fight for social integration processes and a struggle to combat private and public ideologies of inequality. 
$\underline{\text { References }}$

Allport, G. W. (1954). The nature of prejudice. Cambridge, MA: Perseus Books.

Adorno, T. W., Frenkel-Brunswik, E., Levinson, D. J., \& Sanford, R. N. (1950). The authoritarian personality. New York: Harper \& Row.

Agnew, C. R., Thompson, V. D., \& Gaines, Jr., S. O. (2000). Incorporating proximal and distal influences on prejudice: Testing a general model across outgroups. Personality and Social Psychology Bulletin, 26, 403-418.

Altemeyer, B. (1981). Right-wing authoritarianism. Winnipeq: University of Manitoba Press.

Altemeyer, B. (1988). Enemies of freedom: Understanding right-wing authoritarianism. San Francisco: Jossey-Bass.

Anhut, R. \& Heitmeyer, W. (2000). Desintegration, Konflikt und Ethnisierung. Eine Poblemanalyse und theoretische Rahmenkonzeption (Disintegration, conflict and ethniticization. A problem analysis and theoretical frame). In W. Heitmeyer \& R. Anhut (Eds.), Bedrohte Stadtgesellschaft. (Threatened urband society) (pp. 17-25). Weinheim: Juventa.

Bergmann, W., \& Erb, R. (1996). Anti-Semitism in Germany. The post-Nazi epoch from 1945 to 1995. London: Transaction Publishers.

Bierly, M. M. (1985). Prejudice toward contemporary outgroups as a generalized attitude. Journal of Applied Social Psychology, 15, 189-199.

Blumer, H. (1958). Race prejudice as a sense of group position. Pacific Sociological Review, 1, 3-7.

Bobo, L. (1999). Prejudice as group position: Microfoundations of a sociological approach to racism and race relations. Journal of Social Issues, $\underline{55}, 445-472$.

Bratt, C. (2005). The structure of attitudes toward non-western immigrant groups: Second-order factor analysis of attitudes among Norwegian adolescents. Group Processes \& Intergroup Relations, $\underline{8}, 447-469$.

Brewer, M.B. (1999). The psychology of prejudice: Ingroup love and outgroup hate? $\underline{\text { Journal of Social Issues, }}$ 55, 429-444.

Butler, R. N., (1969). Ageism: Another form of bigotry. The Gerontologist, $\underline{9}, 243-$ 246.

Cheung, G. W., \& Rensvold, R.B. (2002) Evaluating Goodness-of-Fit Indexes for Testing Measurement Invariance. Structural Equation Modeling: A Multidisciplinary Journal, 9, 233-255. 
Christ, O. (2006). Systematischer Ausfall im GMF-Panel für die ersten drei Wellen. Unpublished Manuscript, University of Marburg.

Crandall, C. S. (1994). Prejudice against fat people: Ideology and self-interest. Journal of Personality and Social Psychology, 66, 882-894.

Crandall, C. S., \& Eshleman, A. (2003). A justification-suppression model of the expression and experience of prejudice. Psychological Bulletin, 129, 414-446.

Davidov, E., Schmidt, P., Wolf, C., \& Heitmeyer, W. (in prep). Level, Change and Social-Structural Determinants of Group-focused Enmity in Germany.

Devine, P. G., Plant, E. A., \& Harrison, K. (1999). The problem of 'us' versus 'them' and AIDS stigma. American Behavioral Scientist, $\underline{42}$, 1208-1224.

Dovidio, J. F., Brigham, J. C., Johnson, B. T., \& Gaertner, S. L. (1996). Stereotyping, prejudice, and discrimination: Another look. In C. N. Macrae, C. Stangor, \& M. Hewstone (Eds.), Stereotypes and stereotyping (pp. 276-322). New York: Guilford.

Duckitt, J. (2001). A dual-process cognitive-motivational theory on ideology and prejudice. Advances in Experimental Social Psychology, 33, 41-113.

Ekehammar, B., Akrami, N., Gylje, M., \& Zakrisson, I. (2004). What matters most to prejudice: Big five personality, social dominance orientation, or right-wing authoritarianism? European Journal of Personality, 18, 463-482.

Elias, N. \& Scotson, J. L. (1965). The established and the outsiders: a sociological enquiry into community problems. London: Cass.

Greenwald, A. G., McGhee, D. E., \& Schwartz, J. L. K. (1998). Measuring individual differences in implicit cognition: The implicit association test. Journal of Personality and Social Psychology. 74, 1464-1480.

Guimond, S., Dambrun, M., Michinov, N., \& Duarte, S. (2003). Does social dominance generate prejudice? Integrating individual and contextual determinants of intergroup cognition. Journal of Personality and Social Psychology, $\underline{84}$, 697-721.

Heitmeyer, W. (2002). Gruppenbezogene Menschenfeindlichkeit. Die theoretische Konzeption und erste empirische Ergebnisse (Group-focused Enmity. Theoretical conception and first empirical results). In W. Heitmeyer (Ed.), Deutsche Zustände, Folge 1 (German states, Vol. 1) (pp. 15-36). Frankfurt a.M.: Suhrkamp.

Heyder, A., \& Schmidt, P. (2003). Authoritarianism and ethnocentrism in East- and West-Germany - does the system matter? In R. Alba, P. Schmidt, \& M. Wasmer (eds.), Germans or Foreigners? Attitudes toward ethnic minorities in post-reunification Germany (pp. 187-210). New York: Palgrave Macmillan. 
Jöreskog, K. G. (1971). Statistical analysis of sets of congeneric tests, Psychometrika $\underline{36}, 109-133$.

Jöreskog, K. G., \& Sörbom, D. (1977). Statistical models and methods for analysis of longitudinal data. In D. J. Aigner, \& A. S.Goldberger(Eds.) Latent Variables in Socioeconomic Research. Amsterdam: North Holland Publishing.

Jost, J. T., \& Burgess, D. (2000). Attitudinal ambivalence and the conflict between group and system justification motives in low status groups. Personality and Social Psychology Bulletin, 26, 293-305.

Jost, J. T., \& Thomson, E. P. (2000). Group-based dominance and opposition to equality as independent predictors of self-esteem, ethnocentrism, and social policy attitudes among African Americans and European Americans. Journal of Experimental Social Psychology, 36, 209-232.

Hu, L., \& Bentler, P. M. (1999). Cutoff criteria for fit indexes in covariance structure analysis: Conventional criteria versus new alternatives. Structural Equation Modeling: A Multidisciplinary Journal, $\underline{6}, 1-55$.

Kogan, N. (1961). Attitudes toward old people: The development of a scale and an examination of correlates. Journal or Abnormal and Social Psychology, 62, 44-54.

Marsh, H. W., Hau, K. T., \& Wen, Z. (2004). In search of golden rules: Comment on hypothesis-testing approaches to setting cutoff values for fit indexes and dangers in overgeneralizing Hu and Bentler's (1999) findings. Structural equation modeling: A Multidisciplinary Journal, $11,320-341$.

Meloen, J. (1993). The F Scale as a predictor of fascism: An overview of 40 years of authoritarianism research. In W. F. Stone, G. Lederer, \& R. Christie (Eds.), Strength and weakness. The authoritarian personality today (pp. 47-69). New York: Springer-Verlag.

Meredith, W. (1993). Measurement invariance, factor analyses and factorial

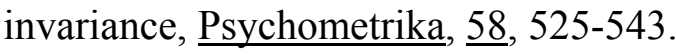

Pettigrew, T. F. (1998). Book review of E. Young-Bruehl's the anatomy of prejudices. Contemporary Psychology, 43, 554-555.

Pettigrew, T. F., Christ, O., Wagner, U., Meertens, R. W., van Dick, R. \& Zick, A. (in press). Relative deprivation and intergroup prejudice. Journal of Social Issues.

Pettigrew, T. F., \& Meertens, R. (1995). Subtle and blatant prejudice in Western Europe. European Journal of Social Psychology, 57, 57-75.

Runciman, W. A. (1966). Relative deprivation and social justice. Berkeley, C.A.: University of California Press. 
Schafer, J. L., \& Graham, J. W. (2002). Missing data: Our view of the state of the art. Psychological Methods, $\underline{7}, 147-177$.

Schuetz, H., \& Six, B. (1996). How strong is the relationship between prejudice and discrimination? A meta-analytic answer. International Journal of Intercultural Relations, $\underline{20}$, 441-462.

Sidanius, J., \& Pratto, F. (1999). Social dominance: An intergroup theory of social hierarchy and oppression. New York, NY, US: Cambridge University Press.

Sidanius, J., Pratto, F., \& Levin, S. (1996). Consensual social dominance orientation and its correlates within the hierarchical structure of American Society. International Journal of Intercultural Relations, 20, 385-408.

Smith, A.W. (1981). Racial tolerance as a function of group position. American $\underline{\text { Sociological Review, } 46,558-573 .}$

Stangor, C., Sullivan, L. A., \& Ford, T. E. (1991). Affective and cognitive determinants of prejudice. Social Cognition, $\underline{9}, 359-380$.

Turner, J., Hogg, M., Oakes, P., Reicher, S., \& Wetherell, M. (1987). Rediscovering the social group: A self-categorization theory. Oxford: Blackwell.

Turner, J. C., Oakes, P. J., Haslam, S. A., \& McGarty, C. (1994). Self and collective: Cognition and social context. Personality and Social Psychology Bulletin, 20, 454-463.

Wagner, U., Christ, O. \& Pettigrew, T. F. (in press). Prejudice and group-related behavior in Germany. Journal of Social Issues.

Wagner, U., van Dick, R., \& Zick, A. (2001). Sozialpsychologische Analysen und Erklärungen der Fremdenfeindlichkeit in Deutschland (Social psychological analyses and explanations of hostility toward strangers in Germany). Zeitschrift für Sozialpsychologie (Journal of Social Psychology), 32, 59-79.

Weigel, R. H., \& Howes, P. W. (1985). Conceptions of racial prejudice: symbolic racism reconsidered. Journal of Social Issues, $\underline{41}$, 117-138.

Weinberger, L.E., \& Millham, J. (1979). Attitudinal homophobia and support of traditional sex roles. Journal of Homosexuality, $\underline{4}$, 237-246.

Whitley, B. E. Jr. (1999). Right-wing authoritarianism, social dominance orientation, and prejudice. Journal of Personality and Social Psychology, 77, 126-134.

Zaller, J.R. (1995). The nature and origins of mass opinion. Cambridge: Cambridge University Press. 
Zick, A., \& Küpper, B. (2005). Transformed anti-Semitism? A report on antiSemitism in Germany. Journal für Konflikt- und Gewaltforschung (Journal of Research on Conflict and Violence), $\underline{7}, 50-92$. 
Figure Captions

Figure 1: $\quad$ The syndrome of GFE with first and second order factors (Cross-section study 2)

Table 1: $\quad$ Means, standard deviations and intercorrelations of all Syndrome-items (data base: cross-section study 2a)

Table 2: $\quad$ Overview hypotheses and strategy of analyses

Figure 2: $\quad$ Specific external validation: The influence of Group Relative Deprivation on several prejudice elements is mediated by Group Focused Enmity 
Figure 1: The syndrome of GFE with first and second order factors (Cross-section study 2)

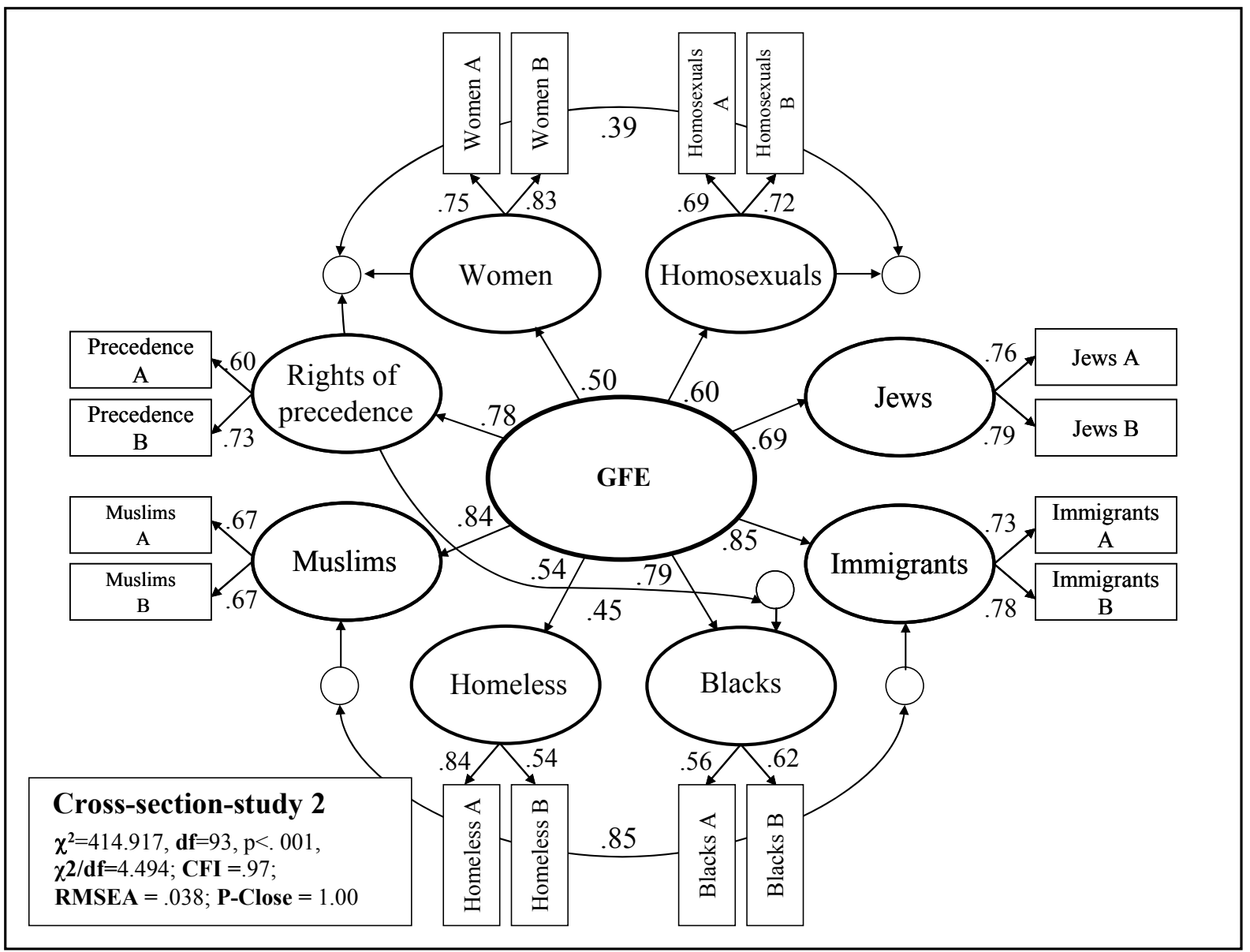


Table 1: Means, standard deviations and intercorrelations of all Syndrome-items (data base: cross-section study 2a)

\begin{tabular}{|c|c|c|c|c|c|c|c|c|c|c|c|c|c|c|c|c|c|c|c|}
\hline Prejudice against... & $\begin{array}{l}\mathrm{M} \\
(\mathrm{SD})\end{array}$ & 1 & 2 & 3 & 4 & 5 & 6 & 7 & 8 & 9 & 10 & 11 & 12 & 13 & 14 & 15 & 16 & 17 & 18 \\
\hline $\begin{array}{l}1 \text { Women: Women should think stronger on the role as } \\
\text { wives and mothers. }\end{array}$ & $\begin{array}{l}1.96 \\
(.90)\end{array}$ & 1.00 & .61 & .34 & .27 & .26 & .21 & .23 & .21 & .26 & .27 & .14 & .09 & .18 & .19 & .23 & .23 & $.05^{*}$ & $.04^{+}$ \\
\hline $\begin{array}{l}2 \text { Women: It is more important for a wife to help her } \\
\text { husband's career than to have one herself. }\end{array}$ & $\begin{array}{l}1.86 \\
(.86)\end{array}$ & & 1.00 &, 33 &, 33 & ,26 & ,22 & ,24 &, 24 & ,29 &, 33 & ,18 &, 11 &, 21 &, 24 & ,23 & ,26 &, $04 *$ &, $02^{+}$ \\
\hline $\begin{array}{l}3 \text { Homosexuals: Marriages between two women or } \\
\text { between two men should be permitted. }\end{array}$ & $\begin{array}{l}2.14 \\
(1.17)\end{array}$ & & & 1.00 & .50 & .26 & .24 & .24 & .23 & .19 & .18 & .18 & .14 & .23 & .26 & .17 & .18 & $-.01^{+}$ & $-.02^{+}$ \\
\hline $\begin{array}{l}4 \text { Homosexuals: It is disgusting when homosexuals kiss } \\
\text { in public. }\end{array}$ & $\begin{array}{l}2.19 \\
(1.10)\end{array}$ & & & & 1.00 & .27 & .24 & .32 & .25 & .18 & .16 & .30 & .23 & .26 & .29 & .21 & .17 & .06 & .06 \\
\hline $\begin{array}{l}5 \text { Jews: As a result of their behaviour, Jewish people } \\
\text { are not entirely without blame for being persecuted. }\end{array}$ & $\begin{array}{l}1.68 \\
(.83)\end{array}$ & & & & & 1.00 & .60 & .33 & .35 & .22 & .32 & .22 & .13 & .30 & .31 & .24 & .28 & $.05^{*}$ & $.00^{+}$ \\
\hline $\begin{array}{l}\text { 6 Jews: Jewish people have too much influence in } \\
\text { Germany }\end{array}$ & $\begin{array}{l}1.91 \\
(.90)\end{array}$ & & & & & & 1.00 & .35 & .32 & .19 & .25 & .21 & .12 & .29 & .31 & .23 & .31 & $.02^{+}$ & $-.01^{+}$ \\
\hline $\begin{array}{l}7 \text { Immigrants: There are too many foreigners living in } \\
\text { Germany. }\end{array}$ & $\begin{array}{l}2.61 \\
(1.01)\end{array}$ & & & & & & & 1.00 & .57 & .25 & .30 & .32 & .23 & .52 & .49 & .35 & .36 & $.05 *$ & $.05^{*}$ \\
\hline $\begin{array}{l}8 \text { Immigrants: When jobs get scarce, the foreigners } \\
\text { living in Germany should be sent home (again). }\end{array}$ & $\begin{array}{l}2.13 \\
(.93)\end{array}$ & & & & & & & & 1.00 & .28 & .30 & .30 & .20 & .44 & .47 & .29 & .39 & .06 & $.01^{+}$ \\
\hline $\begin{array}{l}9 \text { Ethnic group: German re-settlers should be better off } \\
\text { than foreigners because they are of German origin. }\end{array}$ & $\begin{array}{l}.0 \\
1.82 \\
(.83)\end{array}$ & & & & & & & & & 1.00 & .34 & .19 & .12 & .23 & .25 & .22 & .36 & $.05^{*}$ & $.02^{+}$ \\
\hline $\begin{array}{l}10 \text { Ethnic group: It is right that whites are leading in the } \\
\text { world. }\end{array}$ & $\begin{array}{l}1.60 \\
(.81)\end{array}$ & & & & & & & & & & 1.00 & .21 & .10 & .25 & .30 & .22 & .29 & $.05^{*}$ & .06 \\
\hline $\begin{array}{l}11 \text { Homeless: Begging homeless should be chased away } \\
\text { from the pedestrian zone. }\end{array}$ & $\begin{array}{l}2.28 \\
(.98)\end{array}$ & & & & & & & & & & & 1.00 & .45 & .27 & .25 & .21 & .22 & .11 & .08 \\
\hline 12 Homeless: The homeless in the towns are unpleasant. & $\begin{array}{l}2.47 \\
(.91)\end{array}$ & & & & & & & & & & & & 1.00 & .18 & .14 & .12 & .14 & .22 & .23 \\
\hline $\begin{array}{l}13 \text { Muslims: With so many Muslims in Germany, one } \\
\text { feels increasingly like a stranger in one's own country. }\end{array}$ & $\begin{array}{l}2.04 \\
(.98)\end{array}$ & & & & & & & & & & & & & 1.00 & .45 & .24 & .31 & $.05^{*}$ & $.05^{*}$ \\
\hline $\begin{array}{l}14 \text { Muslims: Immigration to Germany should be } \\
\text { forbidden for Muslims. }\end{array}$ & $\begin{array}{l}1.99 \\
(.90)\end{array}$ & & & & & & & & & & & & & & 1.00 & .25 & .31 & $.05^{*}$ & $.00^{+}$ \\
\hline $\begin{array}{l}15 \text { Newcomers: Those who are new somewhere should } \\
\text { be content with less. }\end{array}$ & $\begin{array}{l}2.56 \\
(.96)\end{array}$ & & & & & & & & & & & & & & & & & .07 & .07 \\
\hline $\begin{array}{l}16 \text { Newcomers: Those who have always been living } \\
\text { here should have more rights than those who came later. }\end{array}$ & $\begin{array}{l}2.10 \\
(1.01)\end{array}$ & & & & & & & & & & & & & & & & 1.00 & $.04 *$ & $.04 *$ \\
\hline $\begin{array}{l}17 \text { Disabled: Sometimes I feel uncomfortable in the } \\
\text { presence of handicapped people. }\end{array}$ & $\begin{array}{l}1.96 \\
(.94)\end{array}$ & & & & & & & & & & & & & & & & & 1.00 & .50 \\
\hline $\begin{array}{l}18 \text { Disabled: Sometimes I am unsure how to behave in } \\
\text { face of handicapped people. }\end{array}$ & $\begin{array}{l}2.67 \\
(1.03) \\
\end{array}$ & & & & & & & & & & & & & & & & & & 1.00 \\
\hline
\end{tabular}

Note: ${ }^{*} \mathrm{p}<.05 ;+$ n.s.; all other $\mathrm{p}<.01$ 
Table 2: Overview hypotheses and strategy of analyses

\begin{tabular}{|c|c|c|}
\hline Hypotheses & Analyses & Data base \\
\hline \multicolumn{3}{|c|}{ I) Structure of GFE } \\
\hline \multicolumn{3}{|c|}{ a) Internal structure: Second order factor GFE } \\
\hline $\begin{array}{l}\text { H1: Responses to the prejudice-items } \\
\text { towards nine different outgroups can be } \\
\text { explained by nine first-order factors. }\end{array}$ & $\begin{array}{l}\text { second- order Confirmatory } \\
\text { Factor Analysis (CFA) }\end{array}$ & $\begin{array}{l}\text { main-study } 1, \\
\text { cross-section } 2\end{array}$ \\
\hline $\begin{array}{l}\text { H2: The first- order factors are explained } \\
\text { by one second- order factor. }\end{array}$ & $\begin{array}{l}\text { Cross-validation of the } \\
\text { second- order GFE model }\end{array}$ & $\begin{array}{l}\text { cross-section } 3, \\
\text { panel-wave } 2, \\
\text { panel-wave } 3 \\
\end{array}$ \\
\hline $\begin{array}{l}\mathrm{H} 3 \text { : } \mathrm{H} 1 \text { and } \mathrm{H} 2 \text { are true for all levels of } \\
\text { education. }\end{array}$ & Multiple Group Analyses & cross-section 2 \\
\hline \multicolumn{3}{|c|}{ b) Stability of GFE over time } \\
\hline $\begin{array}{l}\text { H4: Invariance in meaning of prejudice } \\
\text { constructs over time is expected. }\end{array}$ & $\begin{array}{l}\text { Autoregressive panel models } \\
\text { Tests for invariance of item } \\
\text { factor loadings on first- order } \\
\text { factors over time. }\end{array}$ & \multirow{3}{*}{$\begin{array}{l}\text { main-study } 1, \\
\text { panel-wave } 2 \\
\text { panel-wave } 3\end{array}$} \\
\hline $\begin{array}{l}\text { H5: Invariance in the meaning of GFE over } \\
\text { time is not expected. }\end{array}$ & $\begin{array}{l}\text { Autoregressive panel models } \\
\text { Tests for invariance of first- } \\
\text { order factor loadings on } \\
\text { second-order factor GFE over } \\
\text { time. }\end{array}$ & \\
\hline $\begin{array}{l}\text { H6: a) GFE at t } 1 \text { predicts GFE at } \mathrm{t} 2 \text {. GFE } \\
\text { at } \mathrm{t} 2 \text { predicts GFE at } \mathrm{t} 3 \text {. GFE at } \mathrm{t} 1 \text { does } \\
\text { not predict directly GFE at } \mathrm{t} 3 \text {. } \\
\text { b) The stability of the second-order } \\
\text { factor of GFE over time is significantly } \\
\text { positively different from zero. }\end{array}$ & Autoregressive panel models & \\
\hline
\end{tabular}

\section{Common core: Ideology of inequality}

H7: a) The correlation between Social Dominance Orientation and the second-order factor GFE differs from 1.00. b) SDO is strong positive predictor of GFE.

a) Simultaneous second-order CFA, correlation SDO and $\mathrm{GFE}=1.00$ ?; b) Regression cross-section 2 coefficient SDO on GFE

\section{External validation: Common causes, common consequences}

H8: The effect of Authoritarian orientation on eight prejudice components of GFE is fully mediated by the second-order factor of GFE.

H9: Group Relative Deprivation predicts prejudice factors via the second-order factor of GFE.

H10: The second-order factor of GFE predicts specific discriminatory attitudes. 
Figure 2: Specific external validation: The influence of Group Relative Deprivation on several prejudice elements is mediated by Group Focused Enmity

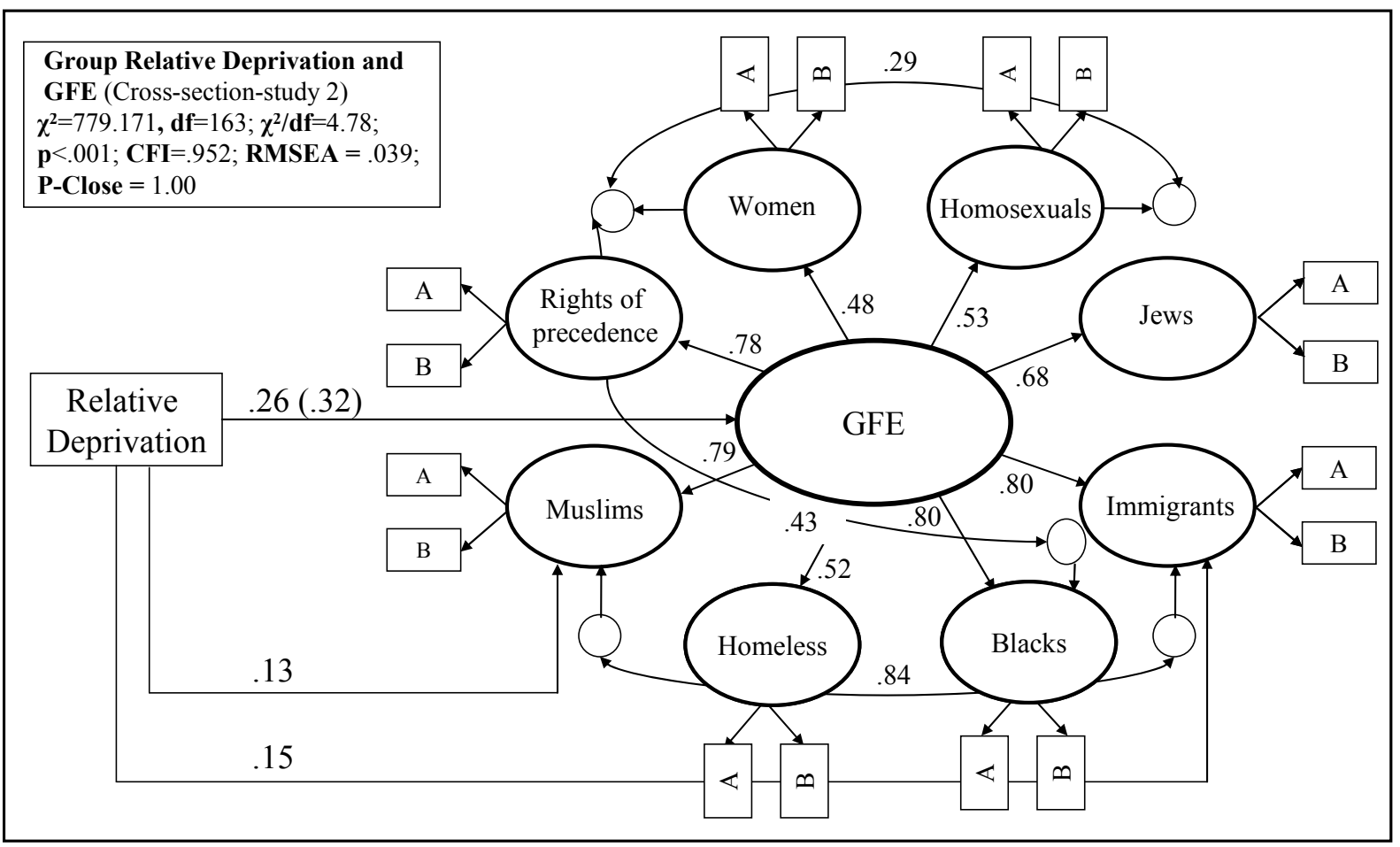

Note: The effect of Relative Deprivation on GFE without accounting for direct effects on attitudes toward Muslims and immigrants is in parenthesis. The fit measures refer to the full model. All coefficients in the model are calculated holding the effect of age, education, gender and income on GFE constant. 
$\underline{\text { About the authors }}$

ANDREAS ZICK is managing the project "Group-focused Enmity in Europe.” From 2006 - 2007 he was heading the Chair of Social Psychology at the University of Technology Dresden. His research interests focus on prejudice, acculturation and intergroup relations.

CARINA WOLF has been a post-graduate in the graduate college of "Group-focused Enmity" at the University of Marburg since 2004. Her research interest is intergroup relations, especially prejudice and intergroup contact.

BEATE KÜPPER is research assistant at the University of Bielefeld and is managing an international project on Group-focused Enmity in Europe. She works on social status and dominance, and interpersonal relations in modernization processes.

ELDAD DAVIDOV is a Post Doc and research assistant at the Central Archive for Empirical Social Research at the University of Cologne. He is interested in economic and social inequality of immigrants, human values in Europe and structural equation modelling.

PETER SCHMIDT is professor for social science methodology in the Department of Political Science at the University of Giessen. His works on structural equation models, panel data, inter-ethnic relations, national identity and environmental behavior.

WILHELM HEITMEYER is professor at the University of Bielefeld and director of the Interdisciplinary Institute for Research on Conflict and Violence. In numerous projects he worked on violence within society and between social groups, right-wing extremism, social disintegration and ethnic segregation. 


\section{ENDNNOTES}

${ }^{1}$ Discrimination by age is also addressed by law, and is currently pre-tested as possible GFE-component.

${ }^{2}$ There is evidence e.g. from research on anti-Semitism that the content of single GFEcomponents might vary over the decades (e.g. racist stereotypes become less salient).

However, this question is not addressed in detail here.

${ }^{3}$ That means we used a "full" data set. Therefore, when we tested the two or three waves together in both cases the $\mathrm{N}$ was 2648 respondents.

${ }^{4}$ In the German questionnaire the group was labelled as „Ausländer“ (“foreigner”), the common expression used in every day language for people living in Germany without German citizenship or Germans with migration background.

${ }^{5}$ According to the criterion of the highest factor loadings, two items were comparably appropriate; the better item in respect of content was chosen as second xenophobia item.

${ }^{6}$ A second order factor analysis is a variation of factor analysis in which the correlation matrix of the common factors is itself factor analyzed to provide a second order factor.

${ }^{7}$ In panel-study 3 we asked the respondents which group they think of considering immigrants in Germany. Roughly two thirds of the respondents think of Turkish immigrants. The largest group of immigrants in Germany consists of people from Turkey, who are predominantly Muslim, and most respondents in fact associate immigrants with Turks.

${ }^{8}$ In this case we take the chi-square difference test into consideration because $\chi^{2} / \mathrm{df}$ was acceptable (lower than three). However, the methodological literature has shown for larger sample sizes as we have chi-square may unjustifiably reject good models. In such cases we will use for model comparison other fit measures (Cheung \& Rensvold, 2002). 
${ }^{9}$ This time we obtained support for the invariance between 2003 and 2004 both for the indicators of the first-order prejudice factors $\left(\chi^{2}=2593.081, \underline{\mathrm{df}}=431, \underline{\mathrm{p}}<.001, \chi^{2} / \mathrm{df}=6.016\right.$, $\underline{\mathrm{CFI}}=.944, \underline{\mathrm{RMSEA}}=.044, \underline{\mathrm{p} \text {-close }}=1.00)$, and between the prejudice factors and the second-order factor GFE $\left(\chi^{2}=2614.504, \underline{\mathrm{df}}=438, \underline{\mathrm{p}}<.001, \chi^{2} / \mathrm{df}=5.969, \underline{\mathrm{CFI}}=.944\right.$, $\underline{\mathrm{RMSEA}}=.043, \underline{\mathrm{p}-\mathrm{close}}=1.00)$.

${ }^{10}$ There was only negligible systematic panel mortality in our data (for details see Christ, 2006). A test of the two panel models with data that included only individuals, who took part in all three waves, did not produce different results. 